\title{
An investigation into genetic and phenotypic variation in time budgets and yield of dairy cows
}

\author{
Peter Løvendahl*1 and Lene Munksgaard $†$ \\ *Department of Molecular Biology and Genetics, and \\ †Department of Animal Science, Aarhus University, DK 8830 Tjele, Denmark
}

\begin{abstract}
Time budgets (TB) of lactating Holstein cows in a freestall loose housing system were recorded twice in early and late lactation to study genetic and phenotypic variation in TB. Time budget traits were recorded using focal animal scanning at 10-min intervals for full 24-h sessions. The study included 243 first-lactation cows, with 389 TB records in early lactation (50 to $123 \mathrm{~d}$ in milk) and 403 records in late lactation (152 to $248 \mathrm{~d}$ in milk). Milk was recorded at 3-wk intervals during the same periods, and yield was expressed as energy-corrected milk. Time budget traits were analyzed with mixed linear models to obtain estimates of genetic variation (heritability) and permanent animal variance (repeatability). Correlations between TB traits and energy-corrected milk yield were estimated at the individual cow level. In early lactation, the cows spent, on average, $5.0 \mathrm{~h}$ eating and $1.8 \mathrm{~h}$ at feed gates without eating while they were still locked in the gates. Cows lay down for $10.4 \mathrm{~h}$ and stood in stalls for $3.2 \mathrm{~h}$. The cows also spent $2.8 \mathrm{~h}$ standing in aisles, but only $0.5 \mathrm{~h}$ in the milking area. In late lactation, cows spent $1 \mathrm{~h}$ more lying, but less time standing in stalls and less time eating and at the feed gates. Time budget traits were moderately repeatable although highly consistent across lactation stages. Estimates of heritability were moderate for eating time $(0.20)$ but almost zero for lying time. Correlations showed that cows with higher yield spent more time eating and less time lying. As there is a trade-off between lying time and eating time, lying time approached lower limits for cows with highest yields. It is suggested that time is viewed as an important but restricted resource that cows may be short of while trying to maintain high yields.
\end{abstract}

Key words: heritability, lying time, eating time, correlated changes

Received May 20, 2015.

Accepted September 8, 2015.

${ }^{1}$ Corresponding author: Peter.Lovendahl@mbg.au.dk

\section{INTRODUCTION}

Recently, genetic selection and improved management has been successful in increasing daily milk yield of dairy cows. However, with increased milk production the cow also has an increased need for energy intake, which may stimulate appetite but also affects time needed for eating and ruminating. More time for eating and rumination can only be obtained by reducing the amount of time spent on other types of behavior, as was found under housed conditions where high-yielding cows spent more time eating but a shorter time lying than low-yielding cows in the same barn (e.g., Fregonesi and Leaver, 2001; Bewley et al., 2010). Similarly, old data suggest that grazing time and time spent ruminating was related to milk production in both Friesian and Jersey cows in all stages of lactation (Brumby, 1959). However, cows may compensate for shorter eating time by becoming faster at eating and ruminating. Biting rate correlated positively with genetic merit for milk yield in Irish Friesians (Bao et al., 1992), and O'Connell et al. (2000) found that high-merit Holstein cows had higher biting rates and spent a greater proportion of time ruminating than medium-merit cows. Thus, with continued selection for higher milk yield, we should expect that cows will develop various strategies to cope with the increased need for energy, although primarily by increasing eating time at the expense of other activities (Ingvartsen et al., 2003).

Time, as well as energy, is a limited resource for the cow, and it can be spent on feed intake and other activities such as walking between different resources, waiting, and resting; thus, high-producing cows that spend more time eating will have less time available for other activities. Currently available experimental evidence for these relationships is scarce and insufficient. Hence, it needs to be investigated whether increased milk production induces a tradeoff situation between eating and other important activities.

Previous results (Munksgaard et al., 2005) showed that, under time constraints, dairy cows chose to spend 
an increased proportion of their available time lying and their feed intake decreased. However, to some degree, the cows compensated for a reduction in eating time by an increased speed of feed intake. Furthermore, experimental manipulation of time budgets (TB) for dairy cows restricting their possibility to lie down has been shown to induce a range of stress responses, such as changes to responsiveness of the hypothalamicpituitary-adrenal axis (Munksgaard and Simonsen, 1996; Fisher et al., 2002) and reduced plasma growth hormone (Munksgaard and Løvendahl, 1993). Furthermore, results by Jensen et al. (2005) showed that heifers were willing to work to obtain 12 to $13 \mathrm{~h}$ of lying time using a demand function experiment. Thus, obtaining sufficient lying time is indeed a high priority in dairy cattle.

External factors, such as the housing conditions and composition of the feed ration, also have an effect on the time allocated to different activities. Improved management practices can help alleviate problems with the TB by reducing waiting time. At the individual level, cows may also differ in previous experience and learned behaviors, which may affect their individual TB, together with their genetic background, including their breeding value for production.

Our hypothesis was that components of the dairy cow TB have genetic variation, and those components closely connected to production traits are both genetically and phenotypically correlated. As such, these components may be affected by genetic differences in the production traits. This experiment was designed to study TB of first-lactation dairy cows, in early and in late lactation, to obtain estimates of phenotypic and genetic variation and correlations to milk yield at the individual level within the early and late stages of lactation.

\section{MATERIALS AND METHODS}

\section{Design and Animals, Housing, and Feeding}

The study included 243 Holstein cows in their first lactation belonging to the Future Genetics Nucleus Herd, kept at the Skølvad Experimental Station (Gredstedbro, Denmark). The herd included first-parity cows that were submitted to a single lactation performance test ending at 305 DIM, after which the cows left the herd. The herd also included Red Dane cows that were kept in the same group but were otherwise not taking part in the study. The cows were offspring of 59 sires and 231 dams with 65 maternal grandsires. The cows were produced by intensive use of multiple ovulation and embryo transfer to give more full-sib groups that improve the ancestry structure for use in genetic stud- ies. Full ancestry of the cows was known for at least 3 generations and was retrieved from the national herd book database.

The animals arrived as heifers at Skølvad at 3 mo of age, coming from the several herds where they were born. They were raised on a diet formulated to restrict growth rate to approximately $800 \mathrm{~g} / \mathrm{d}$. Pregnant heifers were introduced to the dairy barn about 4 mo before expected calving, and were then fed the diet also offered to cows in milk, although in restricted amounts. After calving, the cows were included in the group of milking cows and fed ad libitum on a TMR throughout lactation. Cows were milked mornings and afternoons in a herringbone parlor, where they received supplementary concentrates in fixed amounts of $1.0 \mathrm{~kg}$ per milking. During and following milking, the feed gates were in locking mode from 0430 to $0800 \mathrm{~h}$ and 1500 to $1745 \mathrm{~h}$ to reduce bullying of subordinate and small cows and with a view to avoid contact of newly emptied udders with bedding material. The cows were kept indoors in a freestall barn with at least 1 stall per cow and 1 feeding space per cow. The stalls (length to brisket board $=2.10 \mathrm{~m}$, width $=1.20 \mathrm{~m}$ ) were equipped with mattresses. Cows were allocated to either of 2 groups in the right or left side of the barn (Figure 1), with cows remaining in their group throughout lactation.

\section{Milk Recording}

Milk yields were recorded for $1 \mathrm{~d}$ at 3 -wk intervals, and composite samples from morning and afternoon milkings were assayed for content of fat, protein, lactose, and somatic cells using a CombiFoss 4000 (FossElectric, Hillerød, Denmark) operated by the regional milk recording society (RYK, Varde, Denmark). Yield was expressed as ECM per day, calculated based on yield and composition using the formula of Sjaunja et al. (1990), where lactose was calibrated using the monohydrate form:

$$
\begin{aligned}
\mathrm{ECM}= & \text { milk } \mathrm{kg} \times(383 \times \text { fat } \%+242 \times \text { protein } \% \\
& +157 \times \text { lactose } \%+20.7) / 3,140 .
\end{aligned}
$$

All available milk records obtained in early or late parts of lactation were used for estimating individual cow averages for each part of lactation as described later.

\section{Protocol for Observation of Behavior}

Behavior was observed twice in early and twice in late lactation (Figure 2). Any Holstein cow in the herd was available to and used by the experiment. Cows entered the experiment in the order given by date of 


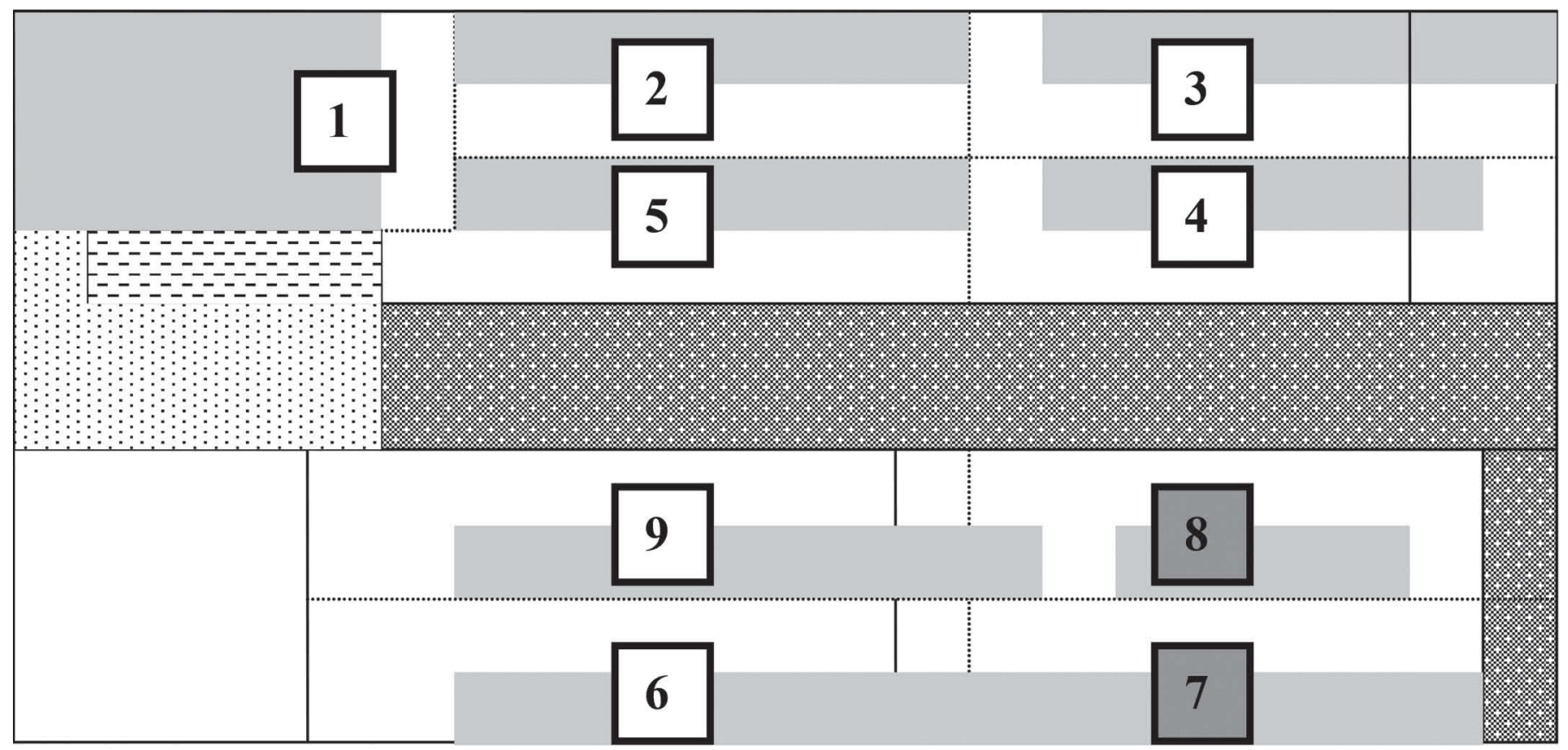

Figure 1. Drawing of barn layout. The barn has 4 rows of stalls (gray), separated by the feed aisle (gray with white dots), floors are solid scraped concrete (white). Codes for zones are in boxes, milking parlor is in zone 1. Zones 7 and 8 were not used for cows in milk. The white dashed area is the exit from the milking parlor, and the white dotted area is a driveway. The white area at the end of zones 6 and 9 is a storage and utility room.

calving. Cows were blocked according to DIM to form batches for observations, giving a total of 39 batches of approximately 20 cows each, with a new batch being observed every month.

The number of cows and recordings of TB and milk production at the early and late stages of lactation are shown in Table 1. Some cows were only recorded at the early and others at the late stage of lactation because the study had fixed start and end dates.

Time budgets were determined from scan sampling of the behavior of each cow in the batch every $10 \mathrm{~min}$ for $24 \mathrm{~h}$. The day before observation of behavior, the cows were equipped with different colored plastic neckbands to improve identification of individual cows. At each scan, the type of activity and the location of each cow were recorded. Combinations of activity and location could fall in any one of the following categories (defined

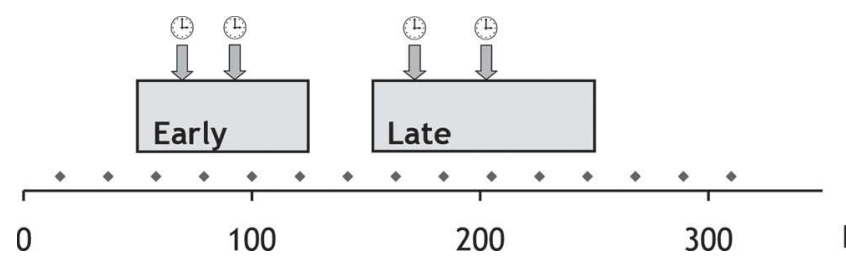

Figure 2. Experimental protocol, with milk recording (diamonds) every 3 wk and time budget recording 2 times in early and 2 times in late lactation (arrows). in Table 2): eating in feed gates, feed gates idle (i.e., not eating), walking or standing in aisles, standing in stall, lying in stall, and standing in the milking parlor area. Around the time of milking, some cows went out of sight. If these cows were observed going into the parlor area they were assumed to be in the parlor, and remain standing until they were observed again. If cows went out of sight at any other time they were coded as such. Time budgets were then expressed as the total time used for each activity and location combination over the 24-h observation period. Bouts of behavioral activity or location were defined as periods without

Table 1. Number of cows and number of recordings of time budget traits and daily milk yield in early and late stages of lactation

\begin{tabular}{lll}
\hline & \multicolumn{2}{c}{ Stage of lactation } \\
\cline { 2 - 3 } Item & Early & Late \\
\hline DIM & $86(21)$ & $189(21)$ \\
Mean (SD) & $50-123$ & $152-248$ \\
Range, overall & $50-108$ & $152-219$ \\
Range, round 1 & $77-123$ & $179-248$ \\
Range, round 2 & & \\
Time budget & 203 & 218 \\
No. of cows & 389 & 403 \\
No. of records & & \\
Milk yield & 243 & 241 \\
$\quad$ No. of cows & 785 & 787 \\
No. of records & & \\
\hline
\end{tabular}


Table 2. Definitions of behavior-location traits and variables for time budgets

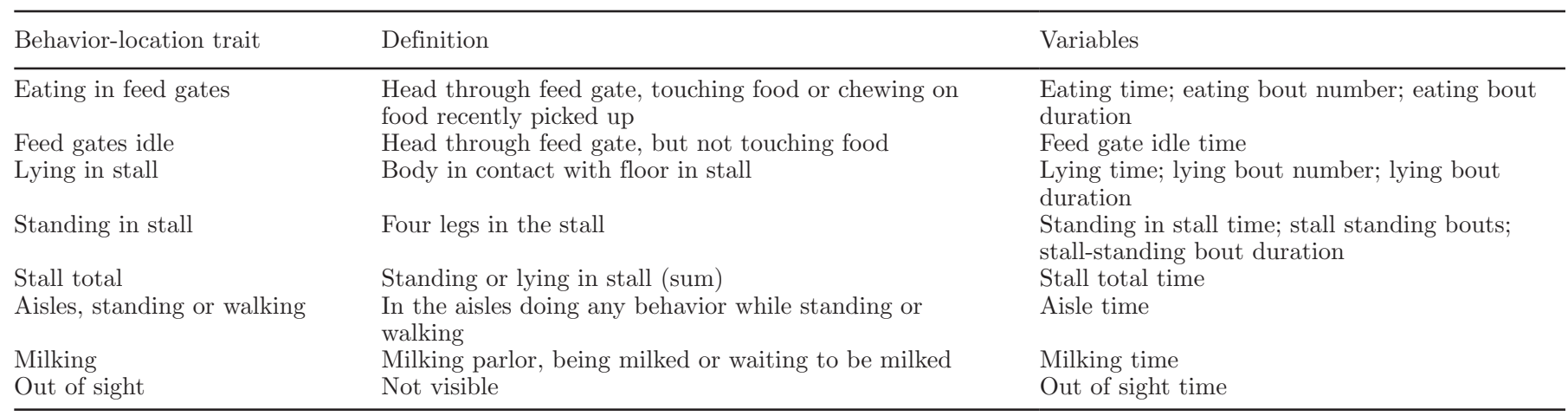

changes in activity or location code (Table 2). The average duration of bouts was calculated as the total duration divided by the number of bouts per $24 \mathrm{~h}$.

\section{Statistical Analysis}

Linear mixed models were used for analysis of milk yield and TB traits, either as single-trait models or as 2-trait models for estimation of correlations between traits. Genetic variance was estimated from single-trait models, as the number of animals in the experiment was insufficient for reliable estimation of genetic covariance between traits. The relationships between yield and TB traits were further assessed as individual level correlations. Relationships between selected TB traits were also assessed as individual level correlations.

Single-Trait Mixed Models. Milk yield (ECM) and TB traits were initially modeled separately within early and late lactation stages (LS) by a repeatability model. The aim was to obtain estimates of genetic variance (heritability) and repeatability over time. Correlations between different traits were obtained from similar 2-trait models (see below). All ECM records within each stage of lactation were included in the analysis. The model [2] for daily milk yield (Y) contained an intercept, $\alpha$, and a fixed factor for the season-year of calving (SYC), defined as 2-mo periods within year. The DIM, seen as the deviation from the mean DIM within lactation stage (early or late), was used as a covariate $\left(b_{1}\right)$. Also, the age at calving in days was included as a fixed covariate after log-e transforming this predictor treated as a covariate $\left(\mathrm{b}_{2} \mathrm{CA}\right)$. Possible effects of climatic and other environmental changes were modeled as a random test-day $\left(\mathrm{TD}_{\mathrm{m}}\right)$ variance. Repeated records of individual cows within stage of lactation $\left(\mathrm{COW}_{\text {iw }}\right)$ were handled as a random effect, as was the residual error term $\left(\varepsilon\right.$ with variance $\left.\sigma_{e}^{2}\right)$ :

$$
\begin{gathered}
\mathrm{Y}=\alpha+\mathrm{SYC}+\mathrm{b}_{1} \mathrm{DIM}+\mathrm{b}_{2} \mathrm{CA}+\mathrm{TD}_{\mathrm{m}} \\
+\mathrm{COW}_{\mathrm{iw}}+\varepsilon .
\end{gathered}
$$

Model [2] was extended to include data from both lactation stages, and a fixed effect of stage (LS) was included, and a further cow across lactation stages component $\left(\mathrm{COW}_{\text {ia }}\right)$ was added to make model [3]:

$$
\begin{aligned}
\mathrm{Y} & =\alpha+\mathrm{SYC}+\mathrm{b}_{1} \mathrm{DIM}+\mathrm{b}_{2} \mathrm{CA}+\mathrm{LS} \\
& +\mathrm{TD}_{\mathrm{m}}+\mathrm{COW}_{\mathrm{ia}}+\mathrm{COW}_{\mathrm{iw}}+\varepsilon .
\end{aligned}
$$

The models [4 and 5] for estimation of genetic variance in milk yield traits extended models [2 and 3$]$ by splitting the individual cow variance further into components of permanent (environmental) cow effects $\left(\mathrm{COW}_{\mathrm{pw}}, \mathrm{COW}_{\mathrm{pa}}\right)$ and an additive genetic effect $\left(\mathrm{COW}_{\mathrm{a}}\right)$ :

$$
\begin{gathered}
\mathrm{Y}=\alpha+\mathrm{SYC}+\mathrm{b}_{1} \mathrm{DIM}+\mathrm{b}_{2} \mathrm{CA}+\mathrm{TD}_{\mathrm{m}} \\
+\mathrm{COW}_{\mathrm{pw}}+\mathrm{COW}_{\mathrm{a}}+\varepsilon \\
\mathrm{Y}=\alpha+\mathrm{SYC}+\mathrm{b}_{1} \mathrm{DIM}+\mathrm{b}_{2} \mathrm{CA}+\mathrm{LS}+\mathrm{TD}_{\mathrm{m}} \\
+\mathrm{COW}_{\mathrm{pa}}+\mathrm{COW}_{\mathrm{pw}}+\mathrm{COW}_{\mathrm{a}}+\varepsilon
\end{gathered}
$$

The models for RB traits followed the yield models $[2$, 3,4 , and 5], having the date of $\mathrm{RB}$ recording as the observation day effect replacing $\mathrm{TD}_{\mathrm{m}}$. The regression on calving age was not included in the analysis of $\mathrm{TB}$ variables as it was always nonsignificant. For the above models, the random (co)variance components were assumed to be normally distributed.

Two-Trait Models for Associations Between Traits. Associations between TB traits and ECM yield were estimated as correlations at the individual level based on covariance components of individual cows $\left(\mathrm{COW}_{\text {iw }}\right)$ obtained from 2 trait models by combining models [2] and [4] within stage of lactation. Milk yield and TB were recorded on separate days; therefore, a covariance between test-day and observation day was nonexistent and, accordingly, the residual covariance remained undefined. Hence, the link between TB traits 
and ECM was only through the individual cows with both traits recorded. Therefore, correlations were estimated at the level of individual cows. Using a similar approach for traits observed in early and late lactation gave estimates of individual level correlations $\left(r_{i}\right)$ as measures of consistency of differences between animals over time. Individual level correlations were also estimated between different TB traits using model [4] within stage of lactation. Estimates of variance and covariance components were obtained using the AIREML algorithm in the DMU package (Madsen and Jensen, 2013).

\section{Genetic and Phenotypic Parameters}

The total phenotypic variance $\left(\sigma_{p}^{2}\right)$ was calculated as the sum of variance components as:

$$
\begin{aligned}
& \sigma_{\mathrm{p}}^{2}=\sigma_{\mathrm{iw}}^{2}+\sigma_{\mathrm{e}}^{2}, \text { or } \\
& \sigma_{\mathrm{p}}^{2}=\sigma_{\mathrm{ia}}^{2}+\sigma_{\mathrm{iw}}^{2}+\sigma_{\mathrm{e}}^{2}, \text { or } \\
& \sigma_{\mathrm{p}}^{2}=\sigma_{\mathrm{a}}^{2}+\sigma_{\mathrm{pw}}^{2}+\sigma_{\mathrm{e}}^{2}, \text { or } \\
& \sigma_{\mathrm{p}}^{2}=\sigma_{\mathrm{a}}^{2}+\sigma_{\mathrm{pa}}^{2}+\sigma_{\mathrm{pw}}^{2}+\sigma_{\mathrm{a}}^{2} ;
\end{aligned}
$$

where variance components are defined as above for the respective models. The heritability was calculated as

$$
\mathrm{h}^{2}=\sigma_{\mathrm{a}}^{2} / \sigma_{\mathrm{p}}^{2}
$$

The repeatability across $\left(t_{a}\right)$ stages and within $\left(t_{w}\right)$ stages of lactation were calculated as

$$
\begin{aligned}
& \mathrm{t}_{\mathrm{a}}=\sigma_{\mathrm{ia}}^{2} / \sigma_{\mathrm{p}}^{2} \text {, and } \\
& \mathrm{t}_{\mathrm{w}}=\sigma_{\mathrm{iw}}^{2} / \sigma_{\mathrm{p}}^{2} \text { or } \mathrm{t}_{\mathrm{w}}=\left(\sigma_{\mathrm{ia}}^{2}+\sigma_{\mathrm{iw}}^{2}\right) / \sigma_{\mathrm{p}}^{2} .
\end{aligned}
$$

Standard errors of genetic parameters were calculated from standard errors and asymptotic covariance among variance components using a Taylor series expansion. Correlated response in time budget variables were estimated as regression coefficients, using the covariance components from the 2 trait models.

\section{RESULTS}

\section{Milk Yield and TB in Early and Late Lactation}

The milk yield increased in early lactation to peak at about $10 \mathrm{wk}$, around the time when the first TB were observed. Following the peak, milk yield declined steadily during the rest of lactation, with an average of $31.3 \mathrm{~kg}$ of ECM in early lactation and $30.3 \mathrm{~kg}$ in late lactation $(P<0.0001)$. Over both lactation stages where TB were recorded, ECM yield showed a linear decrease with advancing DIM $(P<0.05)$ and higher yields were obtained from cows with older age at first calving $(P=0.06)$; however, yields were not affected by season of calving $(P>0.2)$.

\section{Behavior}

Compared with the later stage of lactation, cows in the early stage of lactation spent more time in the feed gates, more time eating, less time in the stall, and less time lying down (Table 3). No differences were observed between stages of lactation in the time spent in the aisles. The number of bouts of both lying and eating decreased from early to late lactation (Table 3). Milking took up less than $1.0 \mathrm{~h} / \mathrm{d}$, including time used in the waiting area, and cows were out of sight on average $0.14 \mathrm{~h}(8 \mathrm{~min})$ per $24 \mathrm{~h}$ observed. Within stage of lactation, lying time and time standing in stalls changed with DIM, which also affected number and duration of lying bouts, similar to the effects of going from early to late lactation (Table 3 ).

\section{Repeatability of Traits Within Lactation Stages and Correlations Between Stages}

Milk yield was highly repeatable within and across stages of lactation (Table 4). In agreement, strong individual correlations were found between early and late stages, showing that cows with high yield in early lactations were consistently high yielding in late lactation (Table 4). Within stage of lactation, all TB variables were only moderately repeatable but individual level correlation between early and late stages were high (Table 4), indicating consistency of animal ranking across stages of lactation. The corresponding bout number and bout duration variables were also moderately repeatable and highly correlated between early and late lactation stages. However, estimates of repeatability for bout number and duration were numerically smaller than for total time used for each behavior within stage of lactation (Table 4). The individual level correlations were always larger than the corresponding repeatability because the estimates excluded the residual variance components.

\section{Estimates of Heritability}

Estimates of heritability for milk yield were low to intermediate at both stages of lactation and the associated standard errors were larger than the estimates themselves (Table 5). At both stages of lactation time budget variables had heritability estimates in the low 
Table 3. Daily milk yield, activity, and time budget traits recorded in early and late lactation ${ }^{1}$

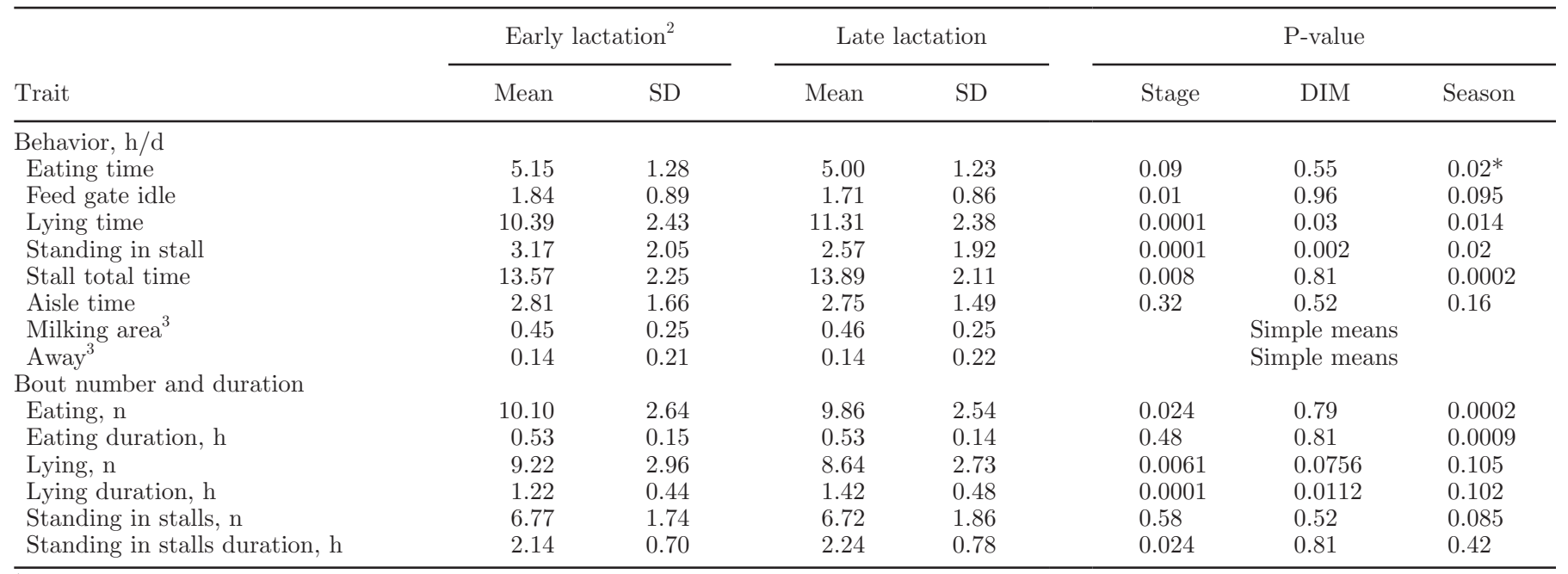

${ }^{1}$ Results are number of records, means and SD, and $P$-values for $F$-test of fixed effects in model [3].

${ }^{2}$ Results are simple means and standard deviations.

${ }^{3}$ Variables were not tested in the model; results are only simple means and SD.

to intermediate range (Table 5) and all estimates had large standard errors. Low heritability estimates were also obtained for bout variables (Table 5). However, time spent eating had heritability at 0.13 to 0.16 and the number of eating bouts had higher heritability, up to 0.31 . In contrast, estimates of heritability for lying time were zero at both stages of lactation, as were the heritability estimates for number and duration of lying bouts.

\section{Correlations with Milk Yield}

Eating time was positively correlated with milk yield and lying time was negatively correlated with milk yield at both stages of lactation (Table 6). However, the negative correlation of lying time with ECM was only significant in early lactation, whereas the positive correlation between ECM and eating time was significant at both stages of lactation and strongest in late lactation. The total time spent in stalls was at both stages of lactation negatively correlated with milk yield. In agreement, higher yield was associated with more and longer eating bouts. Cows with higher yield also had more lying bouts, but these were of shorter duration.

The correlated changes in TB traits (Table 6) showed that, for each extra kilogram of ECM yield, cows were eating for 2.67 and 4.83 more minutes in early and late lactation, respectively. In late lactation, the extra

Table 4. Estimates of repeatability for milk yield and time budget traits, within $\left(\mathrm{t}_{\mathrm{w}}\right)$ and across $\left(\mathrm{t}_{\mathrm{a}}\right)$ lactation stages; and corresponding individual level correlations between lactation traits at 2 lactation stages $\left(\mathrm{r}_{\mathrm{i}}\right)$; results are estimates $\pm \mathrm{SE}$

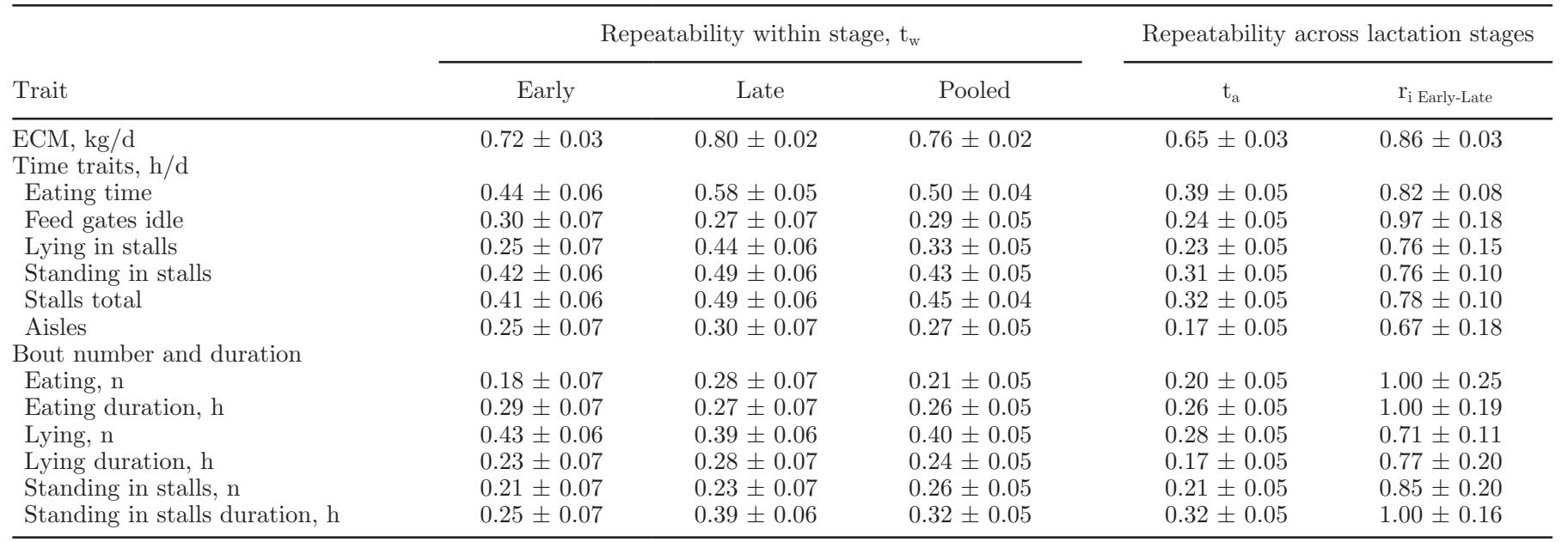


Table 5. Estimates of heritability for milk yield and time budget traits, within and pooled over lactation stages; results are estimates $\pm \mathrm{SE}$

\begin{tabular}{lccc}
\hline & \multicolumn{2}{c}{ Heritability, $\mathrm{h}^{2}$} \\
\cline { 2 - 3 } Trait & Early & Late & Pooled \\
\cline { 2 - 3 } ECM, kg/d & $0.11 \pm 0.16$ & $0.17 \pm 0.17$ & $0.19 \pm 0.16$ \\
Time traits, h/d & $0.13 \pm 0.13$ & $0.16 \pm 0.16$ & $0.20 \pm 0.13$ \\
Eating & $0.13 \pm 0.14$ & $0.07 \pm 0.10$ & $0.06 \pm 0.08$ \\
Feed gates idle & $0.01 \pm 0.10$ & $0.00 \pm 0.15$ & $0.00 \pm 0.10$ \\
Lying in stalls & $0.16 \pm 0.15$ & $0.13 \pm 0.14$ & $0.11 \pm 0.11$ \\
Standing in stalls & $0.10 \pm 0.12$ & $0.11 \pm 0.15$ & $0.07 \pm 0.11$ \\
Stalls total & $0.04 \pm 0.11$ & $0.08 \pm 0.12$ & $0.00 \pm 0.08$ \\
Aisles & & & \\
Bout number and duration & $0.13 \pm 0.11$ & $0.31 \pm 0.17$ & $0.12 \pm 0.09$ \\
$\quad$ Eating, n & $0.09 \pm 0.13$ & $0.09 \pm 0.12$ & $0.06 \pm 0.09$ \\
Eating duration, h & $0.01 \pm 0.11$ & $0.02 \pm 0.11$ & $0.01 \pm 0.09$ \\
Lying, n & $0 \pm 0.12$ & $0.15 \pm 0.14$ & $0.07 \pm 0.08$ \\
Lying duration, h & $0.13 \pm 0.14$ & $0.12 \pm 0.13$ & $0.02 \pm 0.06$ \\
Standing in stalls, n & $0 \pm 0.10$ & $0.39 \pm 0.06$ & $0.05 \pm 0.08$ \\
Standing in stalls duration, h & & & \\
\hline
\end{tabular}

eating time was balanced by losses in time lying and standing in stalls, as well as reduced time in aisles. However, in early lactation the increase in eating time was more than balanced by the decrease in lying time because time standing in stalls also increased, as was time in aisles. At both stages of lactation an increase with yield was found in number of eating bouts and lying bouts; the increased duration of eating bouts was mirrored in shorter lying bouts.

\section{DISCUSSION}

The present study is the first to provide estimates of quantitative genetic variation in full 24-h TB of high-yielding, loose-housed dairy cows and to provide estimates of relationships between animal-related dif- ferences in yield with 24-h TB. The results of the study clearly supports the hypothesis that individual differences in yield are the driving force behind the mutually exclusive exchange of lying time for obtaining more eating time. Because time is a resource limited to 24 $\mathrm{h}$ per day, it appears that the need for both lying time and eating time are less likely to be fulfilled for cows with higher yield.

\section{Relationships Between Milk Yield and TB Traits}

The results of our study confirm the hypothesis that cows with higher yield allocate more time to eating and less time to lying. This confirms previous suggestions of differences in TB between cows from lines selected for high and low milk yield based on daytime TB (Nielsen

Table 6. Estimates of individual level correlations and correlated change in time budget traits with milk yield, at early and late lactation stages; results are estimates $\pm \mathrm{SE}$

\begin{tabular}{|c|c|c|c|c|}
\hline \multirow[b]{2}{*}{ Trait } & \multicolumn{2}{|c|}{ Individual correlations, $r_{i}$} & \multicolumn{2}{|c|}{$\begin{array}{l}\text { Correlated change, } \\
\text { per kg of ECM }\end{array}$} \\
\hline & Early & Late & Early & Late \\
\hline \multicolumn{5}{|l|}{ Time traits, $\min / \mathrm{d}$} \\
\hline Eating & $0.22 \pm 0.10$ & $0.36 \pm 0.08$ & 2.67 & 4.83 \\
\hline Feed gates idle & $-0.03 \pm 0.11$ & $-0.07 \pm 0.12$ & -0.21 & -0.39 \\
\hline Lying in stalls & $-0.25 \pm 0.12$ & $-0.09 \pm 0.10$ & -4.66 & -1.91 \\
\hline Standing in stalls & $0.10 \pm 0.10$ & $-0.07 \pm 0.09$ & 1.79 & -1.40 \\
\hline Stalls total & $-0.14 \pm 0.10$ & $-0.16 \pm 0.10$ & -2.95 & -3.24 \\
\hline Aisles & $0.06 \pm 0.13$ & $-0.07 \pm 0.12$ & 0.79 & -1.33 \\
\hline \multicolumn{5}{|l|}{ Bout number and duration } \\
\hline Eating, n & $0.25 \pm 0.16$ & $0.18 \pm 0.13$ & 0.06 & 0.05 \\
\hline Eating duration, $\min / \mathrm{d}$ & $0.15 \pm 0.13$ & $0.41 \pm 0.13$ & 0.15 & 0.36 \\
\hline Lying, $\mathrm{n}$ & $0.16 \pm 0.10$ & $0.20 \pm 0.10$ & 0.08 & 0.08 \\
\hline Lying duration, $\min / \mathrm{d}$ & $-0.36 \pm 0.14$ & $-0.31 \pm 0.12$ & -1.01 & -1.13 \\
\hline Standing in stalls, $\mathrm{n}$ & $0.10 \pm 0.14$ & $0.01 \pm 0.11$ & 0.13 & 0.00 \\
\hline Standing in stalls duration, $\min / \mathrm{d}$ & $-0.24 \pm 0.14$ & $-0.06 \pm 0.10$ & -0.03 & -0.20 \\
\hline
\end{tabular}


et al., 2000), as well as reduction in lying time with increasing milk in early lactation (Norring et al., 2012). The increase in eating time with increasing level of production corresponded well to the decrease in the time spent in the stalls at both stages of lactation. In late lactation, cows compensated for the extra eating time by reducing both lying and standing time in stalls as well as time in aisles. However, in early lactation, along with the increase in eating time associated with higher yield, a larger decrease was found in lying time and time standing in stalls was increased. This may suggest that the higher yield also was associated with discomfort during lying or in getting up or lying down again. Previous studies suggest that a large amount of milk in the udder may lead to shorter lying time due to discomfort (Österman and Redbo, 2001; Overton et al., 2002). Thus, it is likely that the reduction in lying time was caused both by more time being allocated to eating and by the discomfort from the filled udder. An obvious trade-off between TB traits is caused by the fixed amount of time available, as seen from their quantitative substitution with changes in milk yield. Given the positive correlation between milk yield and eating time, future generations of cows with higher yield can mainly obtain this by reducing their time standing or lying in stalls. This all works in the direction of shortening the duration of bouts in stalls and number of lying bouts, which could be interpreted as a more interrupted resting pattern. We also speculated that this may be due to a limited capacity for feed intake, but this falls beyond the scope of the current study.

\section{TB Traits}

The average number of hours that cows spent lying and eating corresponds to previous findings for cows in loose housing with freestalls (e.g., EFSA, 2009). However, reduced lying time has been associated with crowded conditions (Fregonesi and Leaver, 2002) and with reduced amounts or quality of bedding material (Tucker and Weary, 2004; Drissler et al., 2005). Hardware separations between stalls and floor type have also been shown to affect lying time or lying patterns (Fregonesi and Leaver, 2001; Fregonesi et al., 2009a). In the current experiment, all cows were kept in stalls with mattresses throughout the experimental period and at least one stall was available to each cow to avoid crowding or to restrict possibilities for cows to access stalls; the results are therefore unlikely to be biased by any such effects.

In this specific experimental herd, a relatively long time (almost $2 \mathrm{~h} / \mathrm{d}$ ) was used by the cows in the feed gates without eating during the periods when the gates were locked. Although this was partly intentional by the herd management it also imposed restrictions on cows' possibility to choose to perform other activities during this part of the day, such as lying down in stalls. On the other hand, time used in the waiting area for the milking parlor was short (approximately $0.5 \mathrm{~h}$ ). Thus, although the TB recorded in the present study were only from one herd, which imposed certain restrictions on the cows' behavior, the results show that individual cows differed considerably in their allocation of time to different activities. The observed herd only included first-parity cows and was thereby more homogeneous than commercial herds with cows of mixed parities penned together. The greater homogeneity may have allowed cows to express individual differences without being severely dominated by higher ranking older herd mates and thereby reduced possible bias on variance estimates.

Eating time took up approximately $5 \mathrm{~h}$ per $24 \mathrm{~h}$, consisting of 10 eating bouts with an average duration of 32 min at both stages of lactation. Total eating time as well as number and duration of eating bouts in the present study were similar to previous findings (e.g., Tanida et al., 1984; Fregonesi and Leaver, 2001; DeVries et al., 2003a).

In early lactation, when the yield was higher, the cows tended to spend more time eating and less time in the stalls compared with late lactation. Furthermore, in early lactation the cows were standing for longer when in the stalls, thus the duration of lying was even shorter. Although a similar result was obtained by Fregonesi and Leaver (2002), lactation stage and yield were confounded in their study. The present study was able to separate the effects of yield and stage of lactation by having the same cows observed at both stages and found a highly significant effect of lactation stage on time spent standing in stalls.

\section{Genetic and Individual Variation in TB Traits}

The present study is the first study to provide estimates of quantitative genetic variation in TB traits based on complete 24-h TB records in a larger cohort of housed first-parity Holstein cows. Previously, individual variation in TB traits (i.e., repeatability, Stamer et al., 2000; consistency, Schrader, 2002) was assumed, but the extent to which this had a genetic background was not quantified. However, early studies of identical twins indicated significant similarity within pairs in grazing behavior, including grazing time (Hancock, 1954).

Genetic variation in eating time was evident, with heritability estimates of a magnitude similar to that of milk yield in our study. Eating behavior described as number of eating bouts, or mean eating bout duration, showed heritability of smaller or similar size as total 
eating time. However, the bout information provides further insights to the nature of variation in eating time, as is indicated by each of these traits showing correlations to total eating time of less than one. The consequence is that cows obtain longer eating time through an individually chosen and repeatable combination of number of eating bouts and the duration of each bout, where genetic changes are primarily mediated through the number of bouts.

The cows were lying down almost half the $24 \mathrm{~h}$ observed, but surprisingly almost no genetic variation in the time spent lying was detected. When lying time was described as number of lying bouts, or average lying bouts duration, these derived variables also had almost zero heritability.

In addition to the time spent lying in the stalls, cows also spent $3.2 \mathrm{~h}$ standing in the stalls in early lactation and about $2.6 \mathrm{~h}$ in late lactation. Fregonesi et al. (2009b) reported similar results for older cows in late lactation. Each of the associated standing bouts took about 20 min, which included time to change position from standing to lying and vice versa. A previous study has shown that the ability to get up itself has genetic variation with heritability estimate of $\mathrm{h}^{2}=0.24 \pm 0.08$ [L. Brehmer (Aarhus University), P. Løvendahl, and L. Munksgaard, unpublished results]. Genetic variation in stall standing time was evident and the estimated heritability of intermediate size at both stages of lactation, whereas the associated bout numbers and duration had somewhat lower heritability.

Time budget traits were found to be moderately repeatable across stages of lactation and slightly more repeatable within lactation stages. All estimates of repeatability were larger than corresponding estimates of heritability, indicating that individuality, also called consistency of TB traits, is based to a large extent on permanent animal-related variance. High consistency of lying time bout duration has previously been reported by Schrader (2002). Duration of eating was reported as a highly repeatable trait by Stamer et al. (2000); in agreement, DeVries et al. (2003b) found duration of eating bouts to be highly repeatable. Jointly, these results show that TB traits are moderately repeatable both within and across lactation stages.

\section{Future Ideas}

The findings of unfavorable associations between milk yield, eating time, and lying time indicate that cows are increasingly coming into a conflict situation with continued selection for higher yield. Concurrent findings of reduced fertility in high-yielding cows (e.g., Roxström et al., 2001), as well as increased risk of disease in cows with low BCS (e.g., Lassen et al., 2003), suggest that problems of time shortage may be underlying these problems. However, genetic selection of dairy cows has changed in many populations, from yield being the only trait in the breeding goal to also include fertility and health traits as well as BCS (Miglior et al., 2005). The present study takes another step in the direction of sustainable breeding strategies by assessing time as a resource in line with energy. Time budget traits could therefore be suggested as supplementary indicators to selection indices. Furthermore, TB could also be valuable management tools by monitoring how cows are coping with time constraints during their productive life.

\section{CONCLUSIONS}

This study has shown that eating time of dairy cows is a heritable trait correlated with milk yield, so that cows with higher yield need more time to ingest sufficient feed to sustain their yield. Cows with high yield mainly reduce their lying time or time in stalls to obtain sufficient eating time. As individual differences are reflections of genetic differences, higher yields obtained through selective breeding will continue to induce correlated changes in time budget traits. Although dairy cows probably are able to cope with some reductions in lying or resting time, some may not and those are at increased risk of fatigue syndrome and general loss of welfare.

\section{ACKNOWLEDGMENTS}

The authors are grateful to the persons recording and handling data, Lisbeth Brehmer (Aarhus University), Dorte Lauridsen, Jens Lunde Sørensen (Skølvadgård, Gredstedbro, Denmark), Uffe Thorøe Christensen, and Connie Hårbo Middelhede (Aarhus University), and to colleagues at Aarhus University for advice on statistical analysis and models, Per Madsen and Guosheng $\mathrm{Su}$. We also thank the staff and management (Bjarne Steiner) at Skølvad experimental station (Gredstedbro, Denmark) for excellent keeping of cows that belonged to Future Genetics. Funding was provided from Danish Ministry of Food, Agriculture and Fisheries (Copenhagen) and supplementary funding by the Marie Curie project Optiscore (www.optiscore.eu).

\section{REFERENCES}

Bao, J., P. S. Giller, and J. J. Kett. 1992. The effect of milk production level on grazing behavior of Friesian cows under variable pasture conditions. Ir. J. Agric. Food Res. 31:23-33.

Bewley, J. M., R. E. Boyce, J. Hockin, L. Munksgaard, S. D. Eicher, M. E. Einstein, and M. M. Schutz. 2010. Influence of milk yield, stage of lactation, and body condition on cattle lying behaviour 
measured using an automated activity measuring sensor. J. Dairy Res. 77:1-6.

Brumby, P. 1959. The grazing behaviour of dairy cattle in relation to milk production, live weight, and pasture intake. N. Z. J. Agric. Res. 2:797-807.

DeVries, T. J., M. A. G. von Keyserlingk, D. M. Weary, and K. A Beauchemin. 2003a. Technical note: Validation of a system for monitoring feeding behavior of dairy cows. J. Dairy Sci. 86:35713574 .

DeVries, T. J., M. A. G. von Keyserlingk, D. M. Weary, and K. A. Beauchemin. 2003b. Measuring the behavior of lactating dairy cows. J. Dairy Sci. 86:3354-3361.

Drissler, M., M. Gaworski, C. B. Tucker, and D. M. Weary. 2005. Freestall maintenance: Effects on lying behavior of dairy cattle. J. Dairy Sci. 88:2381-2387.

EFSA (European Food Safety Authority). 2009. Scientific report of EFSA prepared by the Animal Health and Animal Welfare Unit on the effects of farming systems on dairy cow welfare and disease. Annex to the EFSA Journal 1143:1-38.

Fisher, A. D., G. A. Verkerk, C. J. Morrow, and L. R. Matthews. 2002. The effects of feed restriction and lying deprivation on the pituitary-adrenal axis regulation in lactating cows. Livest. Prod. Sci. 73:255-263.

Fregonesi, J. A., and J. D. Leaver. 2001. Behaviour, performance and health indicators of welfare for dairy cows housed in strawyard or cubicle systems. Livest. Prod. Sci. 68:205-216.

Fregonesi, J. A., and J. D. Leaver. 2002. Influence of space allowance and milk yield level on behaviour, performance and health of dairy cows housed in strawyard and cubicle systems. Livest. Prod. Sci. 78:245-257.

Fregonesi, J. A., M. A. G. von Keyserlingk, C. B. Tucker, D. M. Veira, and D. M. Weary. 2009b. Neck rail position in free stall affects standing behavior and udder and stall cleanliness. J. Dairy Sci. 92:1979-1985.

Fregonesi, J. A., M. A. G. von Keyserlingk, and D. M. Weary. 2009a. Cow preference and usage of free stalls compared with an open pack area. J. Dairy Sci. 92:5497-5502.

Hancock, J. 1954. Studies of grazing behaviour in relation to grassland management. I. Variations in grazing habits of dairy cattle. J. Agric. Sci. 44:420-433.

Ingvartsen, K. L., R. J. Dewhurst, and N. C. Friggens. 2003. On the relationship between lactational performance and health: Is it yield or metabolic imbalance that cause production diseases in dairy cattle? A position paper. Livest. Prod. Sci. 83:277-308.

Jensen, M. B., L. J. Pedersen, and L. Munksgaard. 2005. The effect of reward duration on demand functions for rest in dairy heifers and lying requirements as measured by demand functions. Appl. Anim. Behav. Sci. 90:207-217.

Lassen, J., M. Hansen, G. P. Aamand, L. G. Christensen, M. Kargo Sørensen, and P. Madsen. 2003. Genetic relationship between condition score, dairy character, mastitis, and diseases other than mastitis in first-parity Danish Holstein cows. J. Dairy Sci. 86:3730-3735.

Madsen, P., and J. Jensen. 2013. DMU: A User's Guide. A Package for Analysing Multivariate Mixed Models. Accessed Oct. 17, 2015. http://dmu.agrsci.dk/DMU/doc/.
Miglior, F., B. L. Muir, and B. J. Van Doormaal. 2005. Selection indices in Holstein cattle of various countries. J. Dairy Sci. 88:12551263.

Munksgaard, L., M. B. Jensen, L. J. Pedersen, S. W. Hansen, and L. Matthews. 2005. Quantifying behavioural priorities-Effects of time constraints on behaviour of dairy cows, Bos taurus. Appl. Anim. Behav. Sci. 92:3-14.

Munksgaard, L., and P. Løvendahl. 1993. Effects of social and physical stressors on growth hormone levels in dairy cows. Can. J. Anim. Sci. 73:847-853.

Munksgaard, L., and H. B. Simonsen. 1996. Behavioural and pituitary adrenal-axis responses of dairy cows to social isolation and deprivation of lying down. J. Anim. Sci. 74:769-778.

Nielsen, B. L., R. F. Veerkamp, and A. B. Lawrence. 2000. Effects of genotype, feed type and lactational stage on the time budget of dairy cows. Acta Agric. Scand. Anim. Sci. 50:272-278.

Norring, M., A. Valros, and L. Munksgaard. 2012. Milk yield affects time budget of dairy cows in tie-stalls. J. Dairy Sci. 95:102-108.

O'Connell, J. M., F. Buckley, M. Rath, and P. Dillon. 2000. The effects of cow genetic merit and feeding treatment on milk production, herbage intake and grazing behaviour of dairy cows. Ir. J. Agric. Food Res. 39:369-381.

Österman, S., and I. Redbo. 2001. Effects of milking frequency on lying down and getting up behaviour in dairy cows. Appl. Anim. Behav. Sci. 70:167-176.

Overton, M. W., W. M. Sischo, G. D. Temple, and D. A. Moore. 2002. Using time-lapse video photography to assess dairy cattle lying behavior in a free-stall barn. J. Dairy Sci. 85:2407-2413.

Roxström, A., E. Strandberg, B. Berglund, U. Emanuelson, and J. Philipsson. 2001. Genetic and environmental correlations among female fertility traits and milk production in different parities of Swedish Red and White dairy cattle. Acta Agric. Scand. A Anim. Sci. 51:7-14.

Schrader, L. 2002. Consistency of individual behavioural characteristics of dairy cows in their home pen. Appl. Anim. Behav. Sci. $77: 255-266$

Sjaunja, L.-O., L. Baevre, L. Junkkarinen, J. Pedersen, and J. Setälä. 1990. A Nordic proposal for an energy corrected milk (ECM) formula. Pages 156-157 in Performance Recording of Animals: State of the Art 1990. Proceedings of the 27th Biennial session of ICAR. EAAP Publication no. 50. Pudoc, Wageningen, the Netherlands.

Stamer, E., N. Reinsch, and W. Junge. 2000. Merkmale des Fessverhaltens zur Schätzung der Grundfutteraufnahme von Milchkühen unter Laufstallbedingungen. (Traits of feeding behaviour for the estimation of roughage intake of dairy cows under loose housing conditions.) Zuchtungskunde 72:340-358.

Tanida, H., L. V. Swanson, and W. D. Hohenboken. 1984. Effect of artificial photoperiod on eating behavior and other behavioral observations of dairy cows. J. Dairy Sci. 67:585-591.

Tucker, C. B., and D. M. Weary. 2004. Bedding on geotextile mattresses: How much is needed to improve cow comfort? J. Dairy Sci. 87:2889-2895. 